\title{
FORMAÇÃO DAS SUBSTÂNCIAS DE RESERVA DURANTE O DESENVOLVIMENTO DE SEMENTES DE URUCUM (BIXA ORELLANA L. - BIXACEAE)
}

\author{
Lourdes I. V. do Amaral ${ }^{1}$ \\ Maria de Fátima D. A. Pereira ${ }^{2}$ \\ Ângelo L. Cortelazzo ${ }^{3}$
}

Recebido em 31/5/2000. Aceito em 22/9/2000

\begin{abstract}
RESUMO - (Formação das substâncias de reserva durante o desenvolvimento de sementes de urucum, Bixa orellana L. - Bixaceae). As sementes de urucum não germinam durante os primeiros estádios de seu desenvolvimento devido em parte à insuficiência de materiais de reserva. A análise in situ do material de reserva das sementes revelou que ocorrem principalmente proteínas e amido nas células do endosperma. Durante os estádios iniciais do desenvolvimento, o formato dos grãos de amido mostrou-se elíptico, devido a menor quantidade de amilose. Durante o desenvolvimento, os grãos tornaram-se mais esféricos devido ao aumento de amilose em relação a amilopectina. As células do endosperma não possuem corpos protéicos, mas armazenam proteínas. Durante o desenvolvimento houve acúmulo de proteínas dispersas pelo citoplasma. No estádio final do desenvolvimento, as proteínas tornaram-se compactadas devido à desidratação das sementes, que faz parte do processo global de maturação de sementes ortodoxas. A utilização de fluorescência natural revelou a presença de aminoácidos aromáticos no conteúdo protéico, principalmente triptofano e tirosina. Nestas sementes o conteúdo de matéria seca alcançou o máximo quando a semente apresentou cerca de $60 \%$ de umidade. Nesta fase a semente apresentou capacidade germinativa máxima.
\end{abstract}

Palavras-chave - proteína, amido, urucum, sementes, maturação, Bixa

\begin{abstract}
Formation of reserve substances during the development of annatto, Bixa orellana L. - Bixaceae, seeds). Annatto seeds do not germinate during early stages of their development because of insufficient reserve substances. In situ analysis showed that the principal reserves are proteins and starch, deposited in endosperm cells. During the early stages of development, the starch grains were elliptic, because amylose was the minor component. During development, these grains became more spherical due to an increase in amylose relative to amylopectin. Endosperm cells do not contain protein bodies, but they accumulate proteins dispersed in the cytoplasm. At the final stage of development the proteins became compacted due to the dehydration of the seeds wich is part of the
\end{abstract}

1 Professora Assistente do Departamento de Botânica, IB, UnB, ICC SUL Campus Darcy Ribeiro, C. Postal 04467, CEP 70910-900, Brasília, DF, e-mail iamaral@unb.br

2 Professora Titular, Departamento de Fisiologia Vegetal, IB, UNICAMP, C. Postal 6109, CEP 13083-970, Campinas, Sao Paulo, SP

3 Professor Livre Docente, Departamento de Biologia Celular, IB, UNICAMP, C. Postal 6109, CEP 13083-970, Campinas, São Paulo, SP 
global process of orthodox seeds maturation. Natural fluorescence revealed aromatic amino acids, principally tryptophan and tyrosine in the proteins. The seeds reached their maximum dry weight after moisture contents had declined to around $60 \%$. At this point the seeds presented maximum germination capacity.

Key words - protein, starch, annatto, seeds, maturation, Bixa

\section{Introdução}

A idade fisiológica das sementes pode ser caracterizada adequadamente através de alterações que ocorrem durante o seu desenvolvimento. Para essa determinação, os parâmetros mais comumente utilizados são baseados na morfologia interna (Borisjuk et al. 1995), externa e/ou comprimento de frutos e sementes (Walbot et al. 1972; Adams \& Rinne 1981; Figueiredo \& Pereira 1985), no peso fresco e teor de umidade (Pukittayacamee \& Hellum 1988), ou em ambos (Amaral 1990). Segundo Adams \& Rinne (1981), a desidratação impõe o processo de maturação das sementes. As flutuações no conteúdo de água, à medida que ocorre a desidratação, podem causar alterações no metabolismo das sementes (Rosemberg \& Rinne 1986), na quantidade e qualidade dos seus RNA mensageiros (Kermode et al. 1989) e no seu balanço hormonal (Hilhorst \& Karssen 1992; Ni \& Bradford 1993; Kepczynski \& Kepczynska 1997). A maturidade fisiológica é atingida quando as sementes adquirem sua capacidade germinativa, mesmo não tendo terminado seu processo de desenvolvimento e dessecação (Obendorf et al. 1980; Kermode \& Bewley 1986; Miles et al. 1988). Em urucum (Bixa orellana L. - Bixaceae), espécie nativa da América Central e com importância na indústria alimentícia e farmacêutica, foram determinados sete estádios no desenvolvimento das sementes (Amaral 1990). Nessa espécie, a partir do estádio denominado E4, as sementes passam a germinar, mesmo que com tempo médio mais alto do que nos estádios subseqüentes. Além disso, a partir do estádio E6, ocorre um aumento da impermeabilidade do tegumento à água que culmina, no E7, em dormência imposta pelo tégmen, sendo a partir daí, necessária a escarificação das sementes para que as mesmas germinem (Amaral et al. 1995).

O objetivo deste trabalho foi analisar in situ o processo de deposição das substâncias de reserva de sementes em desenvolvimento de Bixa orellana L. - Bixaceae.

\section{Material e métodos}

Foram utilizadas sementes de Bixa orellana, classificadas em sete diferentes estádios de desenvolvimento (E1 a E7), de acordo com o teor de umidade, massa fresca e seca, características morfológicas e capacidade germinativa, segundo Amaral (1990). Sementes nos diversos estádios de desenvolvimento foram separadas em 3 lotes. O primeiro lote foi fixado em FAA50, durante 24 horas e posteriormente usado para observação da fluorescência natural de aminoácidos aromáticos. O segundo lote foi utilizado para a detecção de proteínas, sendo fixado em formaldeído a $4 \%$ durante $24 \mathrm{~h}$ a $5^{\circ} \mathrm{C}$, seguindo-se várias lavagens em água destilada durante 15 minutos. Finalmente, o terceiro lote foi utilizado para detecção de polissacarídeos neutros, sendo fixado em solução de etanol absoluto e ácido acético glacial $3 \mathrm{v} / 1 \mathrm{v}$ por $40 \mathrm{mi}-$ nutos, seguindo-se várias lavagens com água destilada, (Johansen 1940). Após a fixação, as sementes foram desidratadas em álcool butílico terciário, permanecendo em álcool butílico a $70 \%$ por 3 meses. No restante do processo de desidratação, foram necessárias 48 horas de intervalo entre cada troca de álcool (Amaral 1990). As sementes foram então incluídas em parafina e secionada em cortes transversais com $8 \mu \mathrm{m}$ de espessura.

A desparafinização dos materiais foi feita utilizando-se xilol, álcool-xilol 1, metanol-clorofórmio 1:1, hidratação em álcool etílico em 
série decrescente de concentração (de 100 a $50 \%$ ) e água destilada (Johansen 1940). Os cortes dos materiais fixados em FAA50, após desparafinização, foram imersos em óleo não fluorescente (nujol) durante um mínimo de 24h, seguindo-se montagem com lamínula e vedação. A seguir foram observados em microscópio Zeiss de fluorescência, com filtro de excitação com $\lambda=450-490 \mathrm{~nm}$, e filtro de barragem com $\lambda=510-520 \mathrm{~nm}$ para a observação da fluorescência natural. Os cortes fixados em formaldeído a $4 \%$ foram corados durante $15 \mathrm{mi}$ nutos a temperatura ambiente com solução aquosa de ácido acético a 3\% e Xylidine Ponceau a $0,1 \%$ (XP) seguindo-se lavagem em ácido acético $3 \%$ por 30 minutos e água destilada durante 5 minutos, rápida desidratação em etanol 95 e $100 \%$, banho em xilol durante 10 minutos e montagem em bálsamo do Canadá (Cortelazzo \& Vidal 1991). Os cortes fixados em etanolacético foram submetidos ao método PAS. Os cortes foram oxidados durante 10 minutos em ácido periódico $0,5 \%$, lavados em água, imersos em Reativo de Schiff durante 20 minutos, lavados 3 vezes ( 5 minutos cada) em água sulfurosa, desidratados e montados em bálsamo do Canadá. Como controle, cortes foram submetidos ao mesmo tratamento, sem a oxidação prévia pelo ácido periódico (Cortelazzo 1992).

\section{Resultados e discussão}

Os cortes das sementes em desenvolvimento corados pelo PAS evidenciaram no endosperma a presença de polissacarídeos neutros nas paredes celulares e grãos de amido. Durante os primeiros estádios de desenvolvimento (E2), os grãos de amido eram pequenos, com forma elíptica e estavam presentes em pequena quantidade (Fig. 1). A partir de E5 os grãos se tornaram maiores, com formato mais arredondado, estando presentes em grande número (Fig. 2), mantendo esse padrão até E7 (Fig. 3). As paredes celulares do endosperma tornaram-se fortemente coradas (Fig. 2-3). Os cortes utilizados como controle da reação não foram corados por este método.

$\mathrm{O}$ carboidrato de reserva mais comumente encontrado nas sementes é o amido (Singh \& Juliano 1977; Kreis \& Doll 1980), embora polissacarídeos de reserva de parede celular, possam estar presentes chegando a constituíremse no principal carboidrato de reserva (Buckeridge \& Reid 1996). Além disso, as sementes sempre apresentam oligossacarídeos, principalmente da série rafinose, mesmo em pequenas quantidades. Estes oligossacarídeos são o primeiro tipo de reserva a ser metabolizado na fase inicial da germinação (Bewley \& Black 1994). O amido é depositado em organelas subcelulares, denominadas amiloplastos. Seus grãos são semicristalinos e exibem birrefringência em forma de cruz de malta (Banks \& Muir 1980). O formato dos grãos pode variar, desde formas mais esféricas até aquelas bastante elípticas. A forma do grão é em grande parte determinada pelo conteúdo de amilose, pois o grão de amido se torna mais esférico na medida em que ocorre um aumento do conteúdo de amilose em relação ao de amilopectina (Bewley \& Black 1994). Assim, pode-se concluir que no caso de Bixa orellana, ocorre inicialmente um depósito de amilopectina e, apenas em estádios mais avançados, a quantidade de amilose aumenta de forma que, no E5, os grãos de amido se apresentam com quantidades maiores desse homopolissacarídeo e, por isso, com formato mais esférico.

Nas células parenquimáticas do endosperma pode ser notado um acúmulo de material protéico a partir de E2 (Fig. 4). A partir de E4 pode ser observada uma grande quantidade de material XP positivo disperso pelo citoplasma das células (Fig. 5), sendo que esse material sofreu compactação até o estádio E7, quando as sementes apresentavam-se maduras (Fig. 6). O aspecto do material protéico entre o E5 e o E7, indicou diferenças no grau de hidratação dessas moléculas. No E5 elas ainda estavam bastante hidratadas e mais dispersas pelo citoplasma. No E7, as proteínas já se encontravam no seu grau 


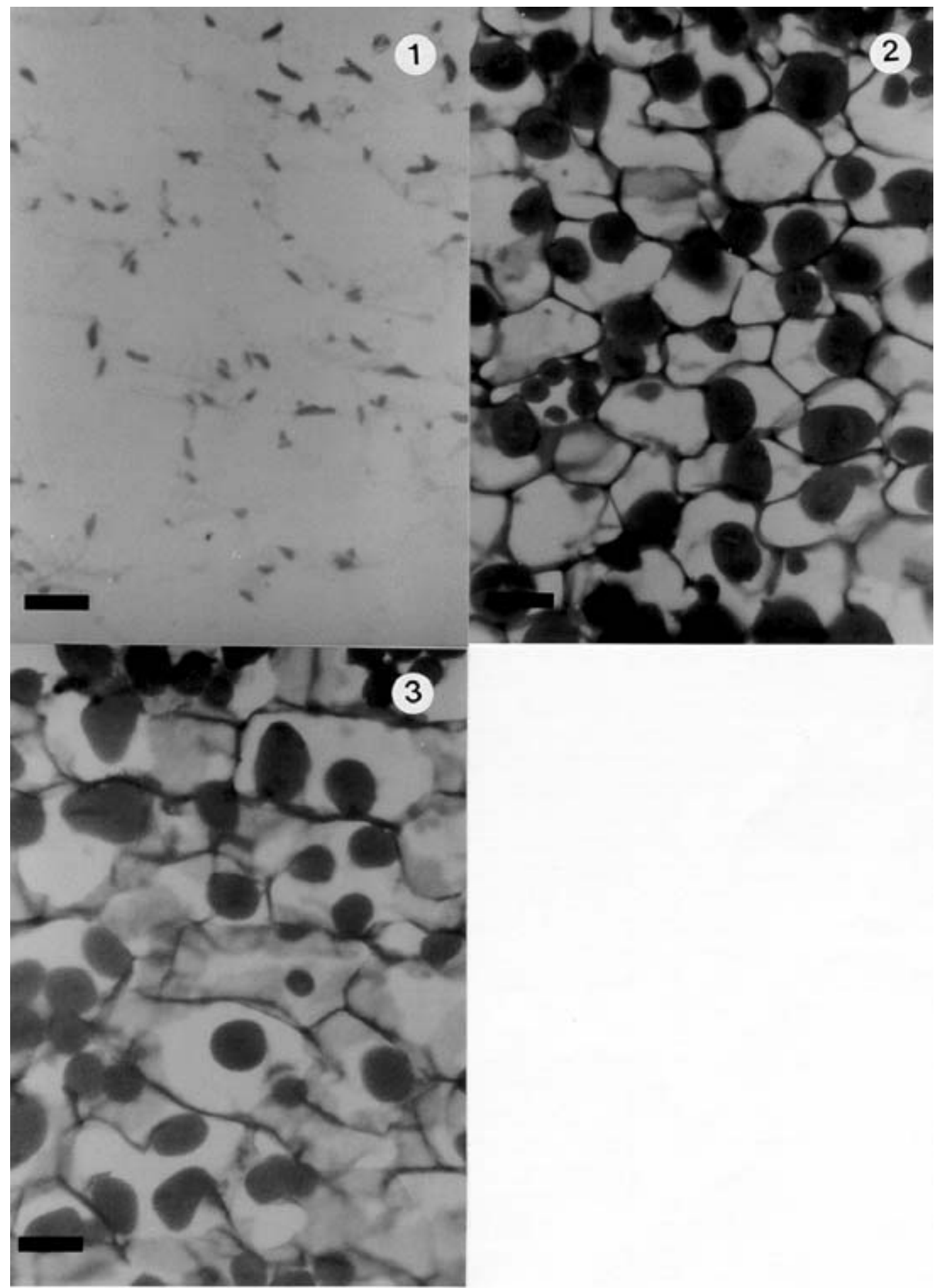

Figuras 1-3. Cortes transversais do endosperma de sementes em desenvolvimento de Bixa orellana L. corados com PAS. 1. E2. Pequenos grânulos de amido elípticos dispersos pelo citoplasma. Notam-se as paredes celulares em início de formação; 2. E5: Grande quantidade de grãos de formato arredondado. Notam-se as paredes celulares completamente formadas; 3. E7. Aspecto dos grãos e paredes celulares idênticos ao do E5. Escala: $20 \mu \mathrm{m}$. 


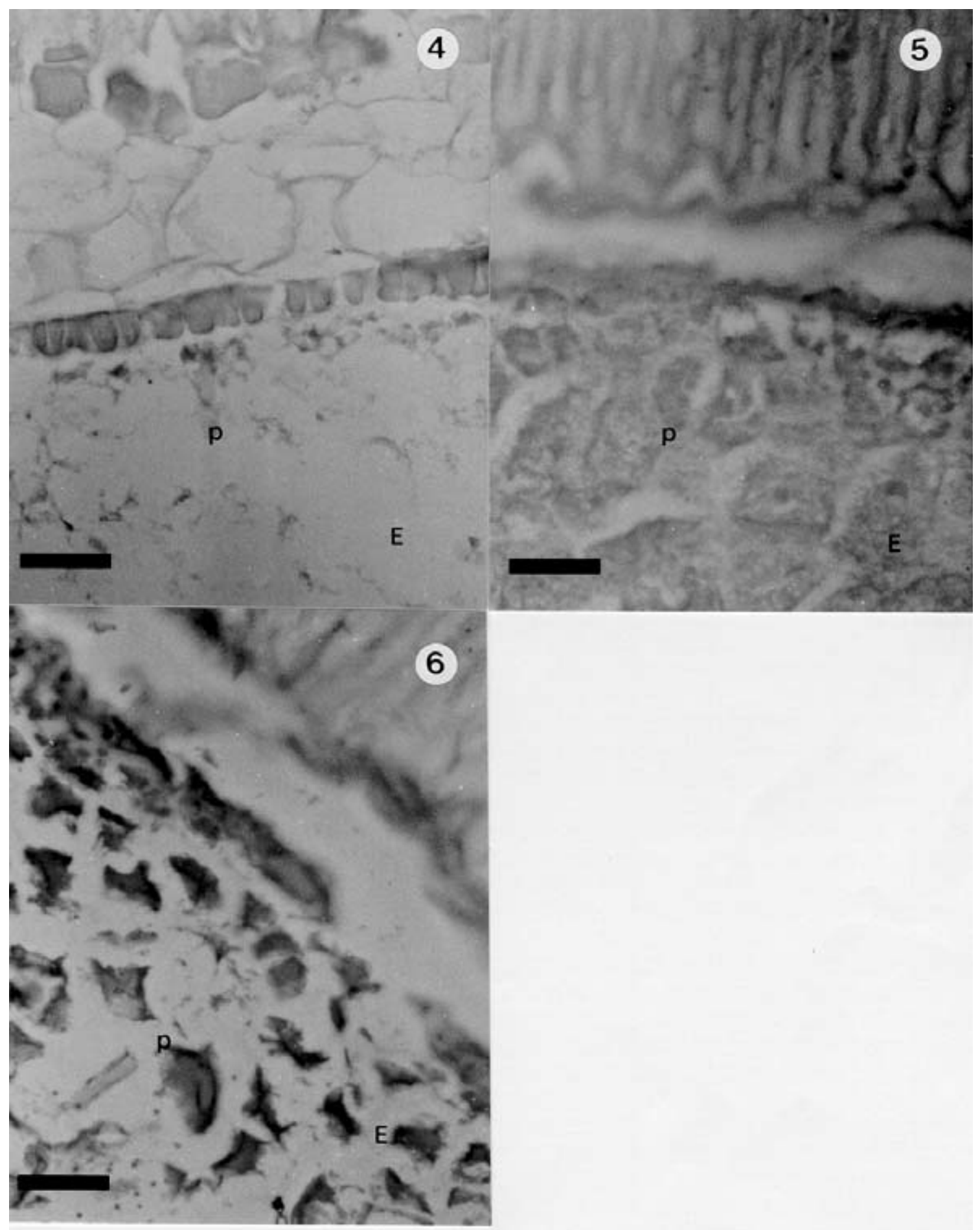

Figuras 4-6. Cortes transversais do endosperma de sementes em desenvolvimento de Bixa orellana L. corados com XP. 4. E2. Endosperma (E) pouco corado pelo XP, apresentando material protéico (p) disperso pelo citoplasma; 5 . E5. Acúmulo de material protéico (p) corado no endosperma (E), ainda pouco compactado; 6. E7. Endosperma (E) fortemente corado pelo XP, apresentando material protéico (p) totalmente compactado. Escala: $35 \mu \mathrm{m}$. 


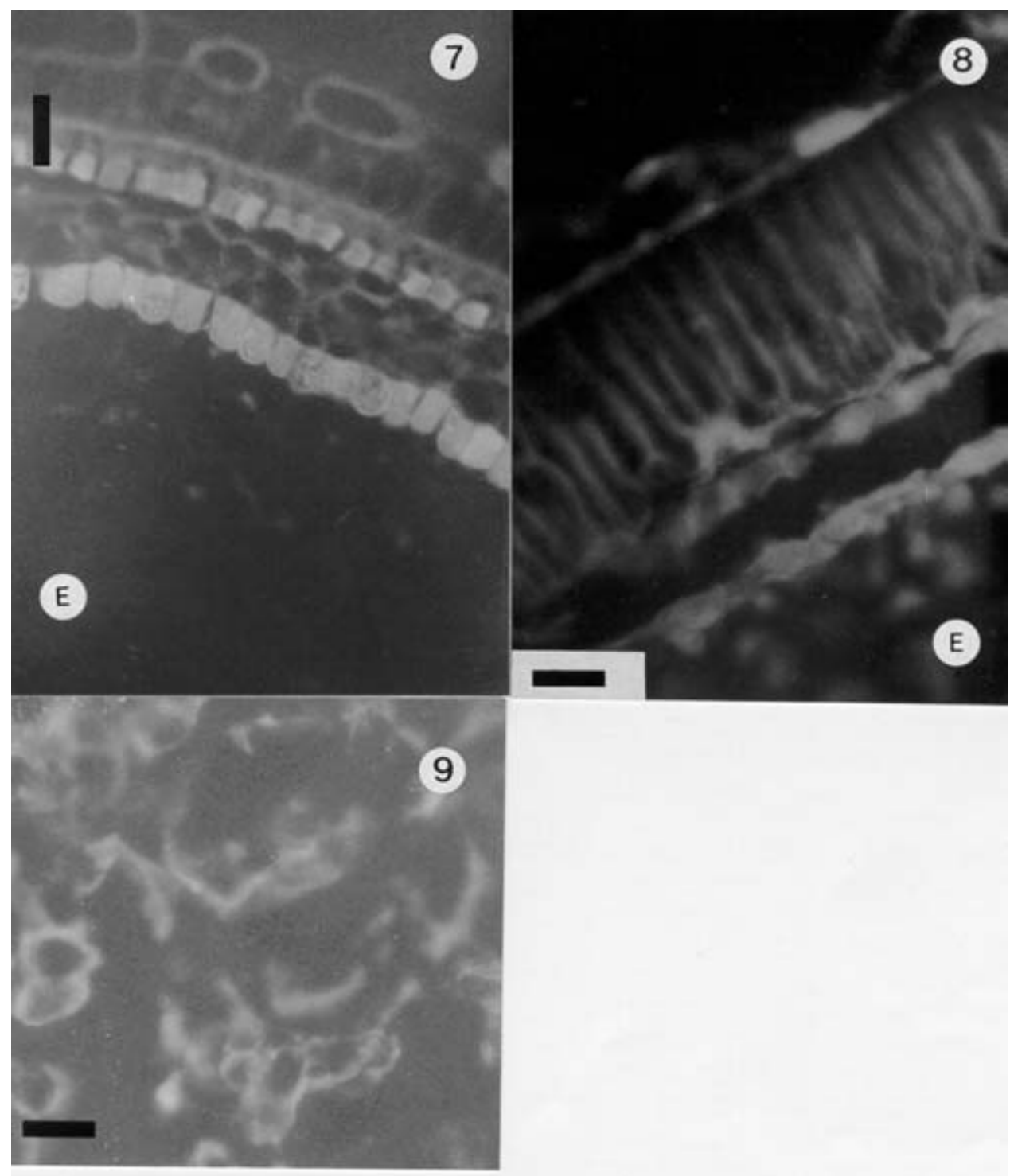

Figuras 7-9. Cortes transversais de sementes em desenvolvimento de Bixa orellana L. observados em microscópio de fluorescência; 7. E1. Endosperma (E) praticamente não fluorescente; 8. E4. Nota-se um acúmulo de material fluorescente nas células do endosperma (E); 9. E4. Detalhe do endosperma com conteúdo máximo de material fluorescente. Escala: $20 \mu \mathrm{m}$.

máximo de desidratação, o que confirma os resultados obtidos para o teor de umidade e a classificação nos diversos estádios feita por Amaral (1990). As proteínas de reserva são geralmente classificadas em função de sua solubilidade. Em cereais, as mais abundantes são as prolaminas e as glutelinas. As primeiras são solúveis em soluções alcoólicas e estão presentes em grande quantidade em milho, sorgo e painço. As glutelinas, são solúveis em soluções ácidas ou básicas diluídas e ocorrem em abundância em trigo, arroz e aveia. Em leguminosas, as globulinas representam a maior parcela das proteínas de reserva e são solúveis em soluções salinas (Derbyshire et al. 1976). A principal função dessas proteínas é fornecer aminoácidos ou nitrogênio para as plântulas em desenvolvimento e, segundo Mayer \& Poljakoff-Mayber (1989), 
estão entre os componentes celulares que mais embebem nas sementes. Assim, diferenças no grau de hidratação das proteínas podem explicar, em parte, porque as sementes do E4 e E5, com acúmulo protéico máximo, embebem a taxas muito inferiores se comparadas com as sementes maduras (E7) escarificadas (Amaral et al. 1995). A detecção de fluorescência natural revelou a presença de aminoácidos aromáticos no conteúdo protéico (Figs. 7, 8 e 9), principalmente triptofano e tirosina, pois a fenilalanina possui excitação máxima a 260nm (Undenfriend 1962) e o filtro de excitação utilizado foi superior a este valor. $\mathrm{O}$ uso deste método revelou o mesmo padrão obtido pelo XP. Há uma tendência de aumento de conteúdo protéico durante os estádios de desenvolvimento. No início há pouco material fluorescente (Fig. 7) e este vai aumentando até o estádio E4, que corresponde ao acúmulo máximo de matéria seca. A partir daí não é mais observado nenhum aumento na fluorescência (Figs. 8 e 9). Os resultados obtidos para o material presente no endosperma justificam o fato de que a partir do E4 as sementes já estão fisiologicamente maduras, pois todo o material de reserva está formado, o que está de acordo com a análise do acúmulo da matéria seca, que atinge o máximo neste estádio. A partir do momento em que a semente está fisiologicamente madura, ela torna-se capacitada a germinar se colocada em condições adequadas de água, gases $\left(\mathrm{O}_{2}\right)$ e temperatura moderada, mesmo que não esteja completamente desidratada (Amaral et al. 1995).

\section{Referências bibliográficas}

Adams, C. A. \& Rinne, R.W. 1981. Seed maturation in soybeans (Glycine max L. Merr.) is dependent of seed mass and the parent plant, yet is necessary for production of viable seeds. Journal of Experimental Botany 32: 615-620.

Amaral, L. I. V. 1990. Germinação e dormência em sementes em desenvolvimento de Bixa orellana L. Aspectos fisiológicos e estruturais. Dissertação de Mestrado. Universidade Estadual de Campinas, Campinas.
Amaral, L. I. V.; Pereira, M. F. A \& Cortelazzo, A. L. 1995. Dormência em sementes de Bixa orellana. Revista Brasileira de Fisiologia Vegetal 7 : 151157.

Banks, W. \& Muir, D. D. 1980. Structure and chemistry of the starch granule. Pp. 321-329. In: P. R. Stumpf, \& E. E. C. (Eds.). The biochemistry of plants. Academic Press, London.

Bewley, J. D. \& Black, M. 1994. Seeds. Physiology of development and germination. 2 ed. Plenum Press, New York.

Borisjuk, L.; Weber, H.; Panitz, R.; Manteuffel, R. \& Wobus, U. 1995. Embryogenesis of Vicia faba L.: Histodifferentiation in relation to starch and storage protein synthesis. Journal of Plant Physiology 147: 203-218.

Buckeridge, M. S. \& Reid, J. S.G. 1996. Major cell wall storage polysaccharides in legume seeds: Structure, catabolism and biological functions. Ciência e Cultura Journal of the Brazilian Association for the Advancement of Science 48(3): 153-162.

Cortelazzo, A. L. 1992. Detecção e quantificação do amido em cotilédones de Canavalia ensiformis e Canavalia gladiata durante o desenvolvimento inicial da planta. Revista Brasileira de Botânica 15: 157-162.

Cortelazzo, A. L. \& Vidal, B. C. 1991. Soybean seed proteins: detection in situ and mobilization during germination. Revista Brasileira de Botânica 14: 27-34.

Derbyshire, E.; Wright, D. J. \& Boulter, D. 1976. Legumin and vicilin, storage proteins of legume seeds. Phytochemistry 15: 3-24

Figueiredo, P. S. \& Pereira, M. F. A. 1985. Immature seeds of Phaseolus vulgaris L. development, germination and reproductive capacity of the resulting plants. Revista Brasileira de Botânica 8: 169-175.

Figueiredo, P. S. \& Pereira, M. F. A. 1990. Germinação de sementes imaturas de Phaseolus vulgaris: envolvimento do ácido abscísico. Revista Brasileira de Botânica 14: 83-88.

Hilhorst, H. W. M. 1993. New aspects of seed dormancy. Proceedings of the Fourth International Workshop on Seeds. Vol. 2, Angers, France. 20-24 pp.

Johansen, D. A. 1940. Plant microtechnique. New York, McGaw.

Kepczynski, J. \& Kepczynska, E. 1997. Ethylene in seed dormancy and germination. Physiologia Plantarum 101(4): 720-726. 
Kermode, A. R. \& Bewley, J. D. 1986. The role of maturation drying in the transition from seed development to germination. IV. Protein synthesis and enzyme activity changes within the cotyledons of Ricinnus comunis L. seeds. Journal of Experimental Botany 38: 1887-1898.

Kermode, A. R.; Pramanik, S. K. \& Bewley, J. D. 1989. The role of maturation drying in the transition from seed development to germination. VI. Desiccationinduced changes in messenger RNA populations within the endosperm of Ricinnus comunis L. seeds. Journal of Experimental Botany 40: 33-4.

Kreis, M. \& Doll, H. 1980. Starch and prolamin level in single and double high lysine barley mutants. Physiologia Plantarum 48: 139-143.

Mayer, A. M. \& Poljakoff-Mayber, A. 1989. The germination of seeds. Pergamon Press, McMillan, New York.

Miles, D. F.; Tekrony, D. M. \& Egli, D. B. 1988. Changes in viability, germination and respiration of freshly harvested soybean seed during development. Crop Sciences 28: 700-704.

Ni, B. R. \& Bradford, K. J. 1993. Germination and dormancy of abscisic acid deficient and gibberellin deficient mutant tomato (Lycopersicon esculentum) seeds - sensitivity of germination to abscisic acid, gibberelin and water potential. Plant Physiology 101(2): 607-617.
Obendorf, R. L.; Asworth, E. N. \& Rytko, G. T. 1980. Influence of seed maturation on germinability in soybean. Crop Sciences 20: 483-486.

Pukittayacamee, P. \& Hellum, A. K. 1988. Seed germination in Acacia auriculiformis: developmental aspects. Canadian Journal of Botany 66: 388-393.

Rosemberg, L. A. \& Rinne, R. W. 1986, Moisture loss as a prerequisite for seedling growth in soybean seeds (Glycine max L. Merr.). Journal of Experimental Botany 37: 1663-1674.

Singh, R. \& Juliano, B. O. 1977. Free sugars in relation to starch accumulation in developing rice grain. Plant Physiology 59: 417-421.

Undenfriend, S. 1962. Fluorescence assay in biology and medicine. Academic Press, New York.

Walbot, V.; Clutter, M. \& Sussex, M. 1972. Reproductive development and embriogeny in Phaseolus. Phytomorphology 22: 59-68. 